\title{
Vapor pressure and thermophysical properties of eugenol and $(+)$-carvone
}

\author{
Sérgio M. Vilas-Boas a, b, c, Václav Pokorný a , Vojtěch Štejfa a, Olga Ferreira ${ }^{\text {b, c }}$, \\ Simão P. Pinho ${ }^{\text {b, c }}$, Květoslav Růžička ${ }^{a}$, Michal Fulem ${ }^{a, *}$ \\ a Department of Physical Chemistry, University of Chemistry and Technology, Technická 5, CZ, 16628, Prague, Czech Republic \\ ${ }^{\mathrm{b}}$ Centro de Investigação de Montanha (CIMO), Instituto Politécnico de Bragança, Campus de Santa Apolónia, 5300-253, Bragança, Portugal \\ ${ }^{c}$ Laboratory of Separation and Reaction Engineering - Laboratory of Catalysis and Materials (LSRE-LCM), Instituto Politécnico de Bragança, Campus de \\ Santa Apolónia, 5300-253, Bragança, Portugal
}

\section{A R T I C L E I N F O}

\section{Article history:}

Received 2 May 2019

Received in revised form

16 July 2019

Accepted 18 July 2019

Available online 20 July 2019

Keywords:

Terpenoids

Vapor pressure

Polymorphic behavior

Heat capacity

\begin{abstract}
A B S T R A C T
In this work, vapor pressures, liquid-phase heat capacities, and phase behavior of two monoterpenoids, $(+)$-carvone and eugenol were studied. The vapor pressure experiments were performed using a static method over an environmentally relevant range of temperatures, from $258 \mathrm{~K}$ to $308 \mathrm{~K}$. Liquid-phase heat capacities were measured by Tian-Calvet calorimetry between $265 \mathrm{~K}$ and $355 \mathrm{~K}$. The phase behavior was investigated by heat-flux differential scanning calorimetry from $183 \mathrm{~K}$. Experimental data were supplemented by ideal-gas thermodynamic properties obtained by combining quantum chemical and statistical thermodynamic calculations. Vapor pressures and heat capacities obtained in this work along with selected literature values were treated simultaneously by multi-property correlation in order to obtain a consistent description of thermodynamically linked properties. To our knowledge, liquid-phase heat capacities and phase behavior of eugenol are reported for the first time in this work.
\end{abstract}

(C) 2019 Elsevier B.V. All rights reserved.

\section{Introduction}

Terpenes and terpenoids belong to a large family of natural compounds that can be found in several organisms, in particular in higher plants $[1,2]$. Besides their application in traditional medicine, these compounds are also important in food processing, flavor, fragrances, agrochemicals, cosmetics, and pharmaceutical industries $[1,3,4]$. In this work, a combined experimental and computational study of thermodynamic properties of two selected monoterpenoids, (+)-carvone ((5S)-5-isopropenyl-2-methyl-2cyclohexen-1-one) and eugenol (2-methoxy-4-prop-2enylphenol), is presented. Eugenol is the major component of several essential oils such as cinnamon leaf oil and clove leaf oil, and, due to its high availability in natural sources, it is preferably isolated from clove oil [5]. (+)-Carvone is the main component of caraway oil and dill oil, being mainly prepared by synthetic methods [6]. Both compounds have direct application as flavor and fragrance compounds, and can also be used as starting materials to produce other valuable derivatives. In particular, one of the most

\footnotetext{
* Corresponding author.

E-mail address: fulemm@vscht.cz (M. Fulem).
}

widespread application of eugenol is in the dentistry, where polymerized eugenol cements formed with the addition of zinc oxide are used for restorative purposes [7]. From an environmental perspective, terpenes and terpenoids are also seen as important biogenic contributors to global secondary organic aerosols (SOAs) $[8,9]$. These aerosols have a direct impact on climate due to their absorption and scattering of solar radiation as well as their influence on the formation of clouds and ice particles [10-12].

In this work, vapor pressure, liquid-phase heat capacity and phase behavior measurements for eugenol and (+)-carvone were performed. To our knowledge, the phase behavior and liquid-phase heat capacities of eugenol are reported for the first time in this work. Ideal-gas thermodynamic properties, required for the multiproperty simultaneous correlation (SimCor) [13], were obtained by combining statistical thermodynamics and density functional theory (DFT) calculations. Based on experimental and theoretical data obtained in this work along with selected literature values, thermodynamically consistent vapor pressure equations for eugenol and enantiopure carvone were developed.

\section{Experimental and theoretical section}

The atomic masses of elements recommended by IUPAC [14] 
Table 1

Sample description.

\begin{tabular}{|c|c|c|c|c|c|}
\hline Name & CAS & Source & {$[\alpha]_{\mathrm{D}}^{20 \mathrm{a}}$} & Mole fraction purity & Mass water content ${ }^{\mathrm{b}}$ \\
\hline$(+)$-Carvone & $2244-16-8$ & Merck & +57.9 & $0.992^{\mathrm{a}} ; 0.991^{\mathrm{c}} ; 0.991^{\mathrm{d}}$ & $50 \cdot 10^{-6}$ \\
\hline Eugenol & $97-53-0$ & Sigma-Aldrich & Achiral & $0.999^{\mathrm{a}} ;>0.9995^{\mathrm{c}} ; 0.9985^{\mathrm{d}}$ & $54 \cdot 10^{-6}$ \\
\hline
\end{tabular}

a Provided by the manufacturer in the certificate of analysis. $[\alpha]_{\mathrm{D}}^{20}$ is specific rotation of neat sample $\left(\right.$ in $\left.\mathrm{degree} \cdot \mathrm{ml} \cdot \mathrm{g}^{-1} \cdot \mathrm{dm}{ }^{-1}\right)$.

b Measured by Karl-Fischer titration using a Metrohm 831 device. The reported value is the average of four determinations.

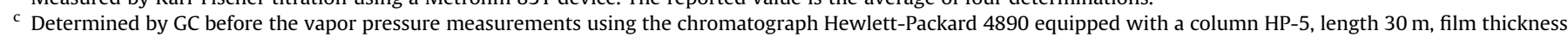
$0.25 \mu \mathrm{m}, 0.32 \mathrm{~mm}$ i.d., and FID detector.

d Determined by GC after the vapor pressure measurements as described in the footnote c.

were used to calculate the molar mass of $(+)$-carvone $\left(M=150.22 \mathrm{~g} \mathrm{~mol}^{-1}\right)$ and eugenol $\left(M=164.20 \mathrm{~g} \mathrm{~mol}^{-1}\right)$. All the temperatures reported in this work are based on the international temperature scale ITS-90. The molar gas constant used in this work is $R=8.3144598 \mathrm{~J} \mathrm{~K}^{-1} \mathrm{~mol}^{-1}$ [15].

\subsection{Materials}

Eugenol and (+)-carvone were used as received except drying over $0.4 \mathrm{~nm}$ molecular sieves. The samples were kept and handled under a dry nitrogen atmosphere in a glove box (MBraun LabStar). The description of the studied samples, including their purity, water content, and methods of purity analysis are summarized in Table 1 . The purity of the samples checked after the vapor pressure measurements is also given in Table 1.

\subsection{Phase behavior studies}

The phase behavior of eugenol and (+)-carvone was investigated using a heat flux differential scanning calorimeter (TA Q1000, TA Instruments). A thorough temperature and enthalpy calibration of the DSC calorimeter was performed using water, gallium, naphthalene, indium, and tin. Samples of 2.5-10 mg (mass determined by an analytical balance with a readability of $0.01 \mathrm{mg}$ ) were sealed hermetically into aluminum pans. Several runs were performed in the temperature interval from $183 \mathrm{~K}$ to $298 \mathrm{~K}$ with various heating rates ranging from 0.5 to $10 \mathrm{~K} \mathrm{~min}^{-1}$. The combined expanded uncertainty ( 0.95 level of confidence) in the determination of phase transition temperatures and enthalpies are estimated to be $0.3 \mathrm{~K}$ and $3 \%$, respectively.

\subsection{Heat capacity measurements}

Liquid-phase heat capacities $\left(C_{p, \mathrm{~m}}^{\mathrm{l}}\right)$ were measured with a TianCalvet calorimeter (SETARAM $\mu$ DSC IIIa, France) with estimated combined expanded uncertainty ( 0.95 level of confidence, $k=2$ ) $U_{\mathrm{c}}\left(C_{p, \mathrm{~m}}\right)=0.01 C_{p, \mathrm{~m}}$. A continuous method [16] with heating rate of $0.3 \mathrm{~K} \mathrm{~min}^{-1}$ was applied in this work as it provides heat capacity data of comparable uncertainty as more time-consuming temperature-increment method [16] for the given calorimeter, as shown by Štejfa et al. [17]. Further details on the heat capacity measurements and the analysis are provided in the Supplementary Data (SD). Experimental heat capacity data points were fitted with a polynomial equation

$$
\frac{C_{p, \mathrm{~m}}^{\mathrm{l}}}{R}=\sum_{i=0}^{n} A_{i+1}\left(\frac{T}{100}\right)^{i}
$$

where $A_{i+1}$ are the fitted coefficients, $R$ is the molar gas constant, and $T$ is the absolute temperature.

\subsection{Vapor pressure measurements}

Vapor pressure measurements were performed using the static apparatus with capacitance diaphragm gauges (internally denoted as STAT6) previously described in detail in Ref. [18]. The combined expanded uncertainty ( 0.95 level of confidence, $k=2$ ) of vapor pressure measurement is adequately described by $U_{\mathrm{c}}(p / \mathrm{Pa})=$ $0.005 p / \mathrm{Pa}+0.05$. Further details on the vapor pressure measurements and data analysis are provided in the SD.

\subsection{Theoretical calculations of ideal-gas thermodynamic properties}

The conformational study, optimization of molecular geometries, energy and harmonic frequency calculations, and scans of potential energy of internal rotations were performed with the Gaussian 09 software [19] using the dispersion-corrected [20] density functional theory (DFT) at the B3LYP-D3/6-311+G(d,p) level of theory. This level of theory was recently proven to give good estimates of relative energies of conformers and vibrational frequencies [21]. The harmonic vibrational frequencies were scaled by a double-linear scaling factor $\left(0.9972-1.48 \cdot 10^{-5} \nu / \mathrm{cm}^{-1}\right) / 0.960$ for frequencies below/above $2000 \mathrm{~cm}^{-1}$ [21] and the ideal-gas thermodynamic properties were subsequently calculated using the recently presented R1SM model [21].

\subsection{Simultaneous treatment of vapor pressures and related thermal data (SimCor method)}

In the SimCor method, the selected experimental vapor pressure data were correlated simultaneously with $\Delta_{1}^{\mathrm{g}} C_{p, \mathrm{~m}}^{0}=C_{p, \mathrm{~m}}^{\mathrm{g} 0}-C_{p, \mathrm{~m}}^{\mathrm{l}}$, where $C_{p, \mathrm{~m}}^{\mathrm{g} 0}$ and $C_{p, \mathrm{~m}}^{\mathrm{l}}$ were obtained by theoretical calculations and from heat capacity measurements, respectively, and "g0" stands for ideal gas and "l" for the liquid phase. The Clarke and Glew equation [22] with four parameters was used to fit the above mentioned thermodynamically linked data

$$
\begin{gathered}
R \ln \frac{p}{p^{0}}=-\frac{\Delta_{\mathrm{l}}^{\mathrm{g}} G_{\mathrm{m}}^{0}(\theta)}{\theta}+\Delta_{\mathrm{l}}^{\mathrm{g}} H_{\mathrm{m}}^{0}(\theta)\left(\frac{1}{\theta}-\frac{1}{T}\right)+\Delta_{\mathrm{l}}^{\mathrm{g}} C_{p, \mathrm{~m}}^{0}(\theta)\left[\frac{\theta}{T}-1+\ln \left(\frac{T}{\theta}\right)\right]+ \\
+\left(\frac{\theta}{2}\right) \frac{\partial \Delta_{\mathrm{l}}^{\mathrm{g}} C_{p, \mathrm{~m}}^{0}}{\partial T}(\theta)\left[\frac{T}{\theta}-\frac{\theta}{T}-2 \ln \left(\frac{T}{\theta}\right)\right]
\end{gathered}
$$


where $\theta=298.15 \mathrm{~K}$ is a reference temperature, $p^{0}=100 \mathrm{kPa}$ is a reference pressure, $R$ is the molar gas constant, and $\Delta_{1}^{\mathrm{g}} G_{\mathrm{m}}^{0}$ and $\Delta_{\mathrm{l}}^{\mathrm{g}} H_{\mathrm{m}}^{0}$ are the standard molar vaporization Gibbs energy and enthalpy, respectively. Since data for evaluation of $p V T$ behavior are not available, $\Delta_{1}^{\mathrm{g}} C_{p, \mathrm{~m}}^{0}$ was only correlated at temperatures where $p<100$ Pa. The SimCor method was described in detail by Rưžička and Majer [13] and for reader's convenience its detailed description is also given in the SD.

\section{Results and discussion}

\subsection{Phase behavior}

Several DSC runs were performed between $183 \mathrm{~K}$ and $298 \mathrm{~K}$ for both compounds with heating rates ranging from 0.5 to $10 \mathrm{~K} \mathrm{~min}^{-1}$. All phase transition enthalpies were calculated by the integration of phase transition peaks, assuming a linear baseline, and the phase change temperatures were determined as the onset temperatures.

Enantiopure carvone is known to occur in three polymorphic forms, two of which are enantiotropically related ( $\mathrm{I} \alpha$ and $\mathrm{I} \beta)$ and the third monotropically related metastable form (II) [23,24]. Our results on the phase behavior are compared with the adiabatic and DSC measurements performed by Gallis et al. [23,24] for (-)-carvone with purity of $99 \%$ in Table 2 . Fusion properties of the metastable phase II could not be identified since it recrystallized to phase $\mathrm{I} \alpha$ in all experiments. The reversible phase transition between phases $\mathrm{I} \beta$ and $\mathrm{I} \alpha$ occurred between $191 \mathrm{~K}$ and $196 \mathrm{~K}$, in accordance with Gallis et al. [23,24]. Thermograms performed with cooling/heating rate of $0.5 \mathrm{~K} \mathrm{~min}^{-1}$ demonstrating a phase behavior of enantiopure carvone are shown in Fig. 1. During the initial cooling (cooling I) a metastable crystalline form II is formed that subsequently transforms to the thermodynamically stable phase I $\alpha$ during heating to $233 \mathrm{~K}$ (heating I). Reversible phase transition between forms $\mathrm{I} \alpha$ and $\mathrm{I} \beta$ then appears on both subsequent cooling and heating steps (cooling II and heating II) followed by melting of phase $\mathrm{I} \alpha$. The transition temperatures and enthalpies determined in this work reasonably agree with the results obtained by Gallis et al. [23] by adiabatic calorimetry (due to a lower uncertainty of measurements by adiabatic calorimetry these values should be considered as reference values).

The temperatures and enthalpies of phase transitions of eugenol are presented in Table 3. To our knowledge, the phase behavior of eugenol is described for the first time in this work. Thermograms

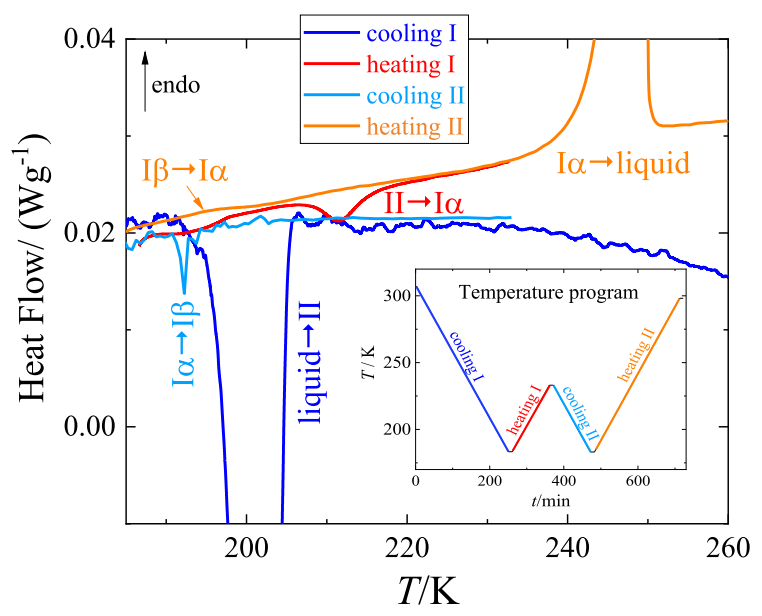

Fig. 1. DSC thermograms for (+)-carvone at cooling/heating rates of $0.5 \mathrm{~K} \mathrm{~min}^{-1}$.

Table 3

Temperatures (in $\mathrm{K}$ ) and enthalpies (in $\mathrm{kJ} \mathrm{mol}^{-1}$ ) of phase transitions of eugenol determined in this work. ${ }^{\mathrm{a}, \mathrm{b}}$

\begin{tabular}{lll}
\hline transition $i \rightarrow j$ & $T_{i \rightarrow j}$ & $\Delta_{i}^{j} H_{\mathrm{m}}^{0}$ \\
\hline glass $\rightarrow$ liquid & $191.4 \pm 0.3$ & - \\
liquid $\rightarrow$ crystal II & 224 to $226^{\mathrm{c}}$ & $\approx-7.6^{\mathrm{c}}$ \\
crystal II $\rightarrow$ crystal I & 233 to $240^{\mathrm{c}}$ & $\approx-6^{\mathrm{c}}$ \\
crystal II $\rightarrow$ liquid & $244.6 \pm 0.3$ & $8.4 \pm 0.3$ \\
crystal I $\rightarrow$ liquid & $261.8 \pm 0.3$ & $17.0 \pm 0.5$ \\
\hline
\end{tabular}

a The combined expanded uncertainties ( 0.95 level of confidence) in the determination of phase transition temperatures and enthalpies are estimated to be $0.3 \mathrm{~K}$ and $3 \%$, respectively. The experiments were performed at $p=(100 \pm 5) \mathrm{kPa}$.

$\mathrm{b}$ All values reported in this table were obtained at heating rate of $0.5 \mathrm{~K} \mathrm{~min}^{-1}$. Thermograms obtained at 2 and $10 \mathrm{~K} \mathrm{~min}^{-1}$ are shown in Fig. S1 in the SD.

${ }^{c}$ Irreversible phase transitions. The temperature interval of the phase transition and corresponding enthalpy value depend on the thermal history and used temperature program.

obtained at a heating rate of $0.5 \mathrm{~K} \mathrm{~min}^{-1}$ (Fig. 2) shows an occurrence of the two monotropically related crystalline forms. Two subsequent DSC runs resulted in two different scenarios: i) glass transition followed by cold crystallization of the metastable crystalline form II and its subsequent melting and ii) glass transition

Table 2

Temperatures (in $\mathrm{K}$ ) and enthalpies (in $\mathrm{kJ} \mathrm{mol}^{-1}$ ) of phase transitions of enantiopure carvone. ${ }^{\mathrm{a}}$

\begin{tabular}{|c|c|c|c|c|c|c|}
\hline \multirow[b]{2}{*}{ transition $i \rightarrow j$} & \multicolumn{2}{|c|}{ This work, DSC ${ }^{\mathrm{a}}$} & \multicolumn{2}{|c|}{ Gallis et al. $[23,24]$, DSC $^{b}$} & \multicolumn{2}{|c|}{ Gallis et al. [23], adiabatic } \\
\hline & $T_{i \rightarrow j}$ & $\Delta_{i}^{j} H_{\mathrm{m}}^{0}$ & $T_{i \rightarrow j}$ & $\Delta_{i}^{j} H_{\mathrm{m}}^{0}$ & $T_{i \rightarrow j}$ & $\Delta_{i}^{j} H_{\mathrm{m}}^{0}$ \\
\hline glass $\rightarrow$ liquid & $-{ }^{\mathrm{d}}$ & - & $171 \pm 1$ & - & 166 & - \\
\hline liquid $\rightarrow$ crystal II & 198 to $211^{\mathrm{e}}$ & $\approx-8.0^{\mathrm{e}}$ & $\approx 193$ & -7.8 & $\approx 179$ & $-8.4^{\mathrm{f}}$ \\
\hline crystal II $\rightarrow$ crystal I $\alpha$ & 208 to $212^{e}$ & $\approx-0.15^{\mathrm{e}}$ & $\approx 210$ & -0.2 & $\approx 202$ & -0.2 \\
\hline crystal I $\beta \rightarrow$ crystal I $\alpha$ & 191 to 196 & $<0.1$ & $\approx 195$ & 0.06 & $\approx 190$ & $-^{\mathrm{g}}$ \\
\hline crystal I $\alpha \rightarrow$ liquid & $246.7 \pm 0.3$ & $11.2 \pm 0.3$ & $247.7 \pm 0.5$ & $11.55 \pm 0.05$ & 249.5 & 11.73 \\
\hline
\end{tabular}

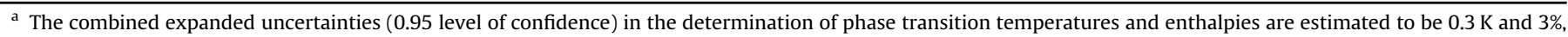
respectively. The experiments were performed at $p=(100 \pm 5) \mathrm{kPa}$.

$\mathrm{b}$ Phase behavior was studied by DSC at heating rate $1.5 \mathrm{~K} \mathrm{~min}^{-1}$.

c Phase behavior was studied by adiabatic calorimetry with the claimed uncertainty of $0.2 \%$.

d Glass transition temperature was not determined in this work as it lies below the operating temperature range of our DSC calorimeter.

e Irreversible phase transitions. The temperature interval of the phase transition and corresponding enthalpy value depend on the thermal history and used temperature

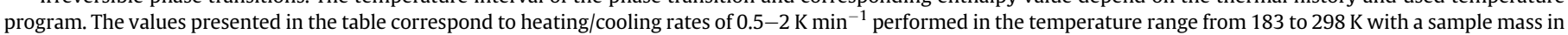
the range $2.5-10 \mathrm{mg}$.

${ }^{\mathrm{f}}$ Crystallization enthalpy of metastable crystal phase II, $\Delta_{\mathrm{l}}^{\mathrm{Il}} H_{\mathrm{m}}^{0}$, was obtained by subtracting the enthalpy $\Delta_{\mathrm{II}}^{\mathrm{I} \alpha} H_{\mathrm{m}}^{0}$ (obtained during a slow-crystallization experiment) from the total crystallization enthalpy.

g Three performed runs were not found reproducible enough to assign value of $\Delta_{\mathrm{l} \beta}^{\mathrm{I} \alpha} H_{\mathrm{m}}^{0}$. 


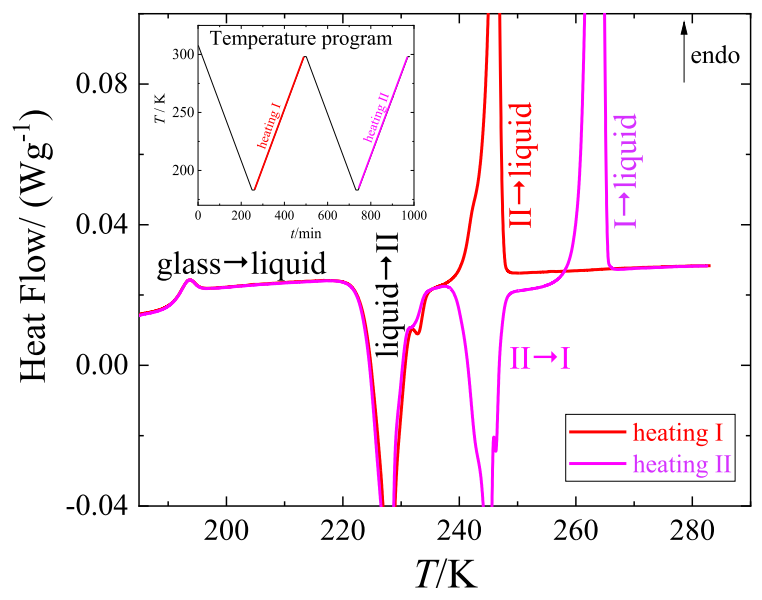

Fig. 2. DSC thermograms for eugenol at cooling/heating rates of $0.5 \mathrm{~K} \mathrm{~min}^{-1}$. Only vitrification was detected on cooling.

followed by cold crystallization of the phase II and subsequent transformation of the phase II to the thermodynamically stable crystalline phase I followed by its melting. In the runs performed with the same temperature program (shown in Fig. 2), these scenarios randomly interchanged. Higher heating/cooling rates, i.e. 2 and $10 \mathrm{~K} \mathrm{~min}^{-1}$, resulted in different scenarios (shown in Fig. S1) such as incongruent melting of metastable phase II leading to formation of the phase I and its subsequent melting (at $2 \mathrm{~K} \mathrm{~min}^{-1}$ ) or a detection of only metastable phase II (at $10 \mathrm{~K} \mathrm{~min}^{-1}$ ).

\subsection{Liquid-phase heat capacities}

The experimental liquid-phase heat capacities obtained in this work using a Tian-Calvet calorimeter in the temperature range from $265 \mathrm{~K}$ to $355 \mathrm{~K}$ are listed in Table 4. Heat capacities of (-)-carvone were previously reported by Gallis et al. [23] in the overlapping temperature range using adiabatic calorimetry with

Table 4

Experimental liquid-phase heat capacities $C_{p, \mathrm{~m}}^{\mathrm{l}}\left(\right.$ in $\left.\mathrm{J} \cdot \mathrm{K}^{-1} \mathrm{~mol}^{-1}\right)$ determined in this work at $p=100 \mathrm{kPa}^{\mathrm{a}}$

\begin{tabular}{|c|c|c|}
\hline & $(+)$-Carvone & Eugenol \\
\hline$T / K$ & $C_{p, \mathrm{~m}}^{\mathrm{l}}$ & $C_{p, \mathrm{~m}}^{\mathrm{l}}$ \\
\hline 265.0 & 264.9 & 311.2 \\
\hline 270.0 & 266.7 & 312.8 \\
\hline 275.0 & 268.7 & 314.5 \\
\hline 280.0 & 270.6 & 315.8 \\
\hline 285.0 & 272.9 & 317.4 \\
\hline 290.0 & 275.2 & 319.2 \\
\hline 295.0 & 277.7 & 321.0 \\
\hline 300.0 & 280.3 & 322.9 \\
\hline 305.0 & 282.7 & 324.8 \\
\hline 310.0 & 284.9 & 326.4 \\
\hline 315.0 & 287.1 & 328.2 \\
\hline 320.0 & 289.5 & 329.9 \\
\hline 325.0 & 292.1 & 331.7 \\
\hline 330.0 & 294.3 & 333.3 \\
\hline 335.0 & 296.5 & 334.8 \\
\hline 340.0 & 298.2 & 336.1 \\
\hline 345.0 & 299.7 & 337.1 \\
\hline 350.0 & 301.1 & 338.2 \\
\hline 355.0 & 302.0 & 339.1 \\
\hline
\end{tabular}

a The standard uncertainty (0.68 level of confidence) of the temperature measurement is $u(T)=0.05 \mathrm{~K}$, and the combined expanded uncertainty of the heat capacity is $U_{c}\left(C_{p, \mathrm{~m}}\right)=0.01 C_{p, \mathrm{~m}}$ (0.95 level of confidence). Mean values of four determinations are presented in the table.
Table 5

Parameters of polynomial Eq. (1).

\begin{tabular}{|c|c|c|c|c|c|c|}
\hline Compound & $A_{1}$ & $A_{2}$ & $A_{3}$ & $A_{4}$ & $\left(T_{\min }-T_{\max }\right) / \mathrm{K}$ & $\sigma^{\mathrm{a}} / \%$ \\
\hline (+)-carvone & 97.2443 & -76.7196 & 27.9412 & -3.1438 & $250-355$ & 0.34 \\
\hline eugenol & 109.8312 & -79.2825 & 27.7269 & -3.0628 & $265-355$ & 0.04 \\
\hline $\begin{array}{c}{ }^{\mathrm{a}} \sigma \text { is the } \\
100\left\{\sum_{i=1}^{n}\left[\left(C_{p, \mathrm{~m}}^{l}\right.\right.\right.\end{array}$ & $\begin{array}{r}\text { standard } \\
\left.-C_{p, \mathrm{~m}}^{\mathrm{l}, \text { calc }}\right) / C\end{array}$ & $\begin{array}{c}\text { relative } \\
\text { l,calc }]_{i}^{2} /(n-\end{array}$ & $\begin{array}{l}\text { deviation } \\
m)\}^{1 / 2}, \text { wh }\end{array}$ & $\begin{array}{l}\text { of the } \\
\text { here } n \text { is th }\end{array}$ & $\begin{array}{l}\text { fit defined a } \\
\text { e number of fitt }\end{array}$ & $\begin{array}{l}\sigma= \\
\text { ed data }\end{array}$ \\
\hline
\end{tabular}

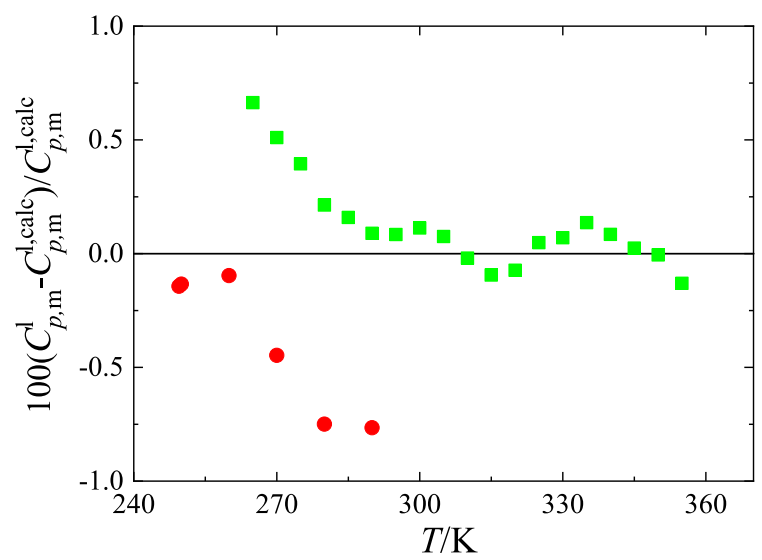

Fig. 3. Deviations of experimental liquid-phase heat capacities $C_{p, \mathrm{~m}}^{\mathrm{l}}$ from the values $C_{p, \mathrm{~m}}^{\mathrm{l}, \mathrm{m}}$ calculated using Eq. (1) for enantiopure carvone. $\ldots$, this work $((+)$-carvone), $\bullet$ Gallis et al. [23] ((-)-carvone).

the estimated uncertainty of $0.002 C_{p, \mathrm{~m}}^{\mathrm{l}}$. To our knowledge, no heat capacity data for eugenol were reported in the literature. Data obtained in this work and those reported by Gallis et al. [23] were considered in the SimCor method and correlated together by Eq. (1) over a combined temperature interval. The resulting parameters and the standard deviations of the fit are presented in Table 5. Deviations of the experimental data from the correlation equation, Eq. (1), for enantiopure carvone are displayed in Fig. 3. The agreement between liquid-phase heat capacities obtained in this work with those reported by Gallis et al. [23] is within their uncertainties (the deviations do not exceed $0.8 \%$ ). We note that in the critical review of liquid-phase heat capacities by Zábranský et al. [25], the authors assigned the uncertainties of $0.005 C_{p, \mathrm{~m}}^{\mathrm{l}}$ to liquid-phase heat capacities measured by the adiabatic calorimeter used by Gallis et al. [23].

\subsection{Vapor pressures}

Prior to the vapor pressure measurements, the samples were thoroughly degassed in the STAT6 apparatus by repeating measuring cycles, as discussed in more detail in Ref. [17]. This procedure also lead to distilling-off volatile impurities. The vapor pressure measurements were performed from $258 \mathrm{~K}$ to $308 \mathrm{~K}$ for (+)-carvone and from $273 \mathrm{~K}$ to $308 \mathrm{~K}$ for eugenol. In the studied temperature range, both eugenol and $(+)$-carvone were in the liquid phase. The experimental vapor pressure data obtained in this work and from literature are listed in Table 6 and Table 7, respectively.

The data for enantiopure carvone are compared using the arc representation [26] in Fig. 4a. The data measured by Batiu and coworkers [27-29] as a part of VLE studies using a circulation still are in good agreement mutually and with our results, but their earliest data [27] seem to diverge at lower temperatures and were therefore not considered in the SimCor method. The static 
Table 6

Experimental vapor pressures determined by STAT 6 apparatus. ${ }^{a}$

\begin{tabular}{|c|c|c|c|c|c|}
\hline$T / \mathrm{K}$ & $p / \mathrm{Pa}^{\mathrm{b}}$ & $\Delta p / \mathrm{Pa}^{\mathrm{c}}$ & $T / \mathrm{K}$ & $p / \mathrm{Pa}^{\mathrm{b}}$ & $\Delta p / \mathrm{Pa}^{\mathrm{c}}$ \\
\hline \multicolumn{3}{|c|}{ (+)-Carvone (liquid phase) } & \multicolumn{3}{|c|}{ Eugenol (liquid phase) } \\
\hline 258.18 & 0.197 & -0.010 & 273.70 & 0.153 & 0.004 \\
\hline 258.18 & 0.202 & -0.005 & 273.70 & 0.153 & 0.004 \\
\hline 258.18 & 0.201 & -0.006 & 273.70 & 0.152 & 0.003 \\
\hline 263.19 & 0.371 & 0.004 & 278.19 & 0.252 & 0.003 \\
\hline 263.19 & 0.371 & 0.004 & 278.19 & 0.251 & 0.002 \\
\hline 263.19 & 0.373 & 0.006 & 278.19 & 0.252 & 0.003 \\
\hline 268.18 & 0.653 & 0.018 & 283.19 & 0.451 & 0.020 \\
\hline 268.18 & 0.656 & 0.021 & 283.19 & 0.443 & 0.012 \\
\hline 268.19 & 0.653 & 0.017 & 283.19 & 0.444 & 0.013 \\
\hline 273.19 & 1.096 & 0.021 & 288.19 & 0.723 & -0.007 \\
\hline 273.19 & 1.096 & 0.021 & 288.19 & 0.724 & -0.006 \\
\hline 273.19 & 1.097 & 0.022 & 288.19 & 0.725 & -0.005 \\
\hline 273.69 & 1.133 & 0.002 & 293.20 & 1.256 & 0.048 \\
\hline 273.69 & 1.138 & 0.007 & 293.20 & 1.233 & 0.025 \\
\hline 273.70 & 1.141 & 0.008 & 293.20 & 1.223 & 0.015 \\
\hline 278.19 & 1.788 & 0.011 & 298.20 & 1.930 & -0.027 \\
\hline 278.19 & 1.789 & 0.012 & 298.20 & 1.938 & -0.019 \\
\hline 278.19 & 1.790 & 0.013 & 298.20 & 1.934 & -0.023 \\
\hline 283.19 & 2.902 & 0.026 & 303.20 & 3.070 & -0.037 \\
\hline 283.19 & 2.899 & 0.023 & 303.20 & 3.081 & -0.026 \\
\hline 283.19 & 2.893 & 0.017 & 303.20 & 3.077 & -0.030 \\
\hline 288.19 & 4.581 & 0.016 & 308.20 & 4.871 & 0.030 \\
\hline 288.20 & 4.579 & 0.010 & 308.21 & 4.864 & 0.019 \\
\hline 288.20 & 4.587 & 0.018 & 308.21 & 4.868 & 0.023 \\
\hline 293.20 & 7.151 & 0.036 & & & \\
\hline 293.20 & 7.137 & 0.022 & & & \\
\hline 293.20 & 7.137 & 0.022 & & & \\
\hline 298.20 & 10.90 & 0.01 & & & \\
\hline 298.20 & 10.90 & 0.01 & & & \\
\hline 298.21 & 10.90 & 0.00 & & & \\
\hline 303.20 & 16.37 & -0.01 & & & \\
\hline 303.20 & 16.38 & 0.00 & & & \\
\hline 303.20 & 16.38 & 0.00 & & & \\
\hline 308.21 & 24.13 & -0.14 & & & \\
\hline 308.21 & 24.15 & -0.12 & & & \\
\hline 308.21 & 24.15 & -0.12 & & & \\
\hline
\end{tabular}

a The standard (0.68 level of confidence) uncertainty of the temperature measurement is $u(T)=0.02 \mathrm{~K}$, and the combined expanded uncertainty $(0.95$ level of confidence) of the vapor pressure measurement is $U_{c}(p / \mathrm{Pa})=0.005 p+0.05$.

b Values are reported with one digit more than is granted by the experimental uncertainty to avoid rounding errors in further calculations.

c $\Delta p=\left(p-p_{\text {calc }}\right)$, where $p_{\text {calc }}$ is calculated from the Clarke and Glew equation, Eq. (2), with parameters given in Table 11 .

measurements by Guetachew et al. [3] are in significant disagreement with our measurements and show inconsistency with the heat capacity data. For these reasons the vapor pressure data for reported by Guetachew et al. [3] were not considered in the SimCor method. We note that for other terpenes studied in our previous works $[17,30,31]$ the vapor pressure data measured by Guetachew and collaborators were always in a very good agreement with our measurements. Other data sources [32,33] for enantiopure carvone were rejected from the SimCor method due to their high scatter.

Vapor pressure data for eugenol recently reported by Russo et al. [34] show systematic negative deviations from our data by $11 \%$ on average and a worse consistency with $\Delta_{1}^{\mathrm{g}} C_{p, \mathrm{~m}}^{0}=C_{p, \mathrm{~m}}^{\mathrm{g} 0}-C_{p, \mathrm{~m}}^{\mathrm{l}}$ values as can be seen in Fig. 4b. A single data point obtained by gas chromatography was also reported by van Roon et al. [35] (the deviation amounts to about 50\%). The determination of vapor pressures by gas chromatography has a significantly higher uncertainty than our static measurements, as discussed in detail in Refs. [36-38]. For these reasons, none of the abovementioned vapor pressure data sets reported for eugenol was included in the treatment by the SimCor method.

\subsection{Ideal-gas thermodynamic properties}

A conformational analysis, a prerequisite step in the calculation of ideal-gas thermodynamic properties, was performed in a similar way as in our recent study of menthol [39]. Since five of the ring atoms in carvone are almost coplanar, only two ring conformations were found to be stable, with isopropenyl top in equatorial (labeled as EQ) and axial (AX) positions. The dihedral angles defining the position of the isopropenyl group were labeled according to Fig. 5 (describing the dihedral angle following Cahn-Ingold-Prelog priority rules) as gauche $\left(\mathrm{g}, 60^{\circ}\right)$, antigauche $\left(\mathrm{g}^{\prime},-60^{\circ}\right)$ or trans $(\mathrm{t}$, $180^{\circ}$ ). Six conformers were found to be stable in agreement with the previous studies summarized in Table 8. In early experimental studies [40,41], EQ conformers of carvone were found to be more stable than AX conformers using circular dichroism spectra. The relative enthalpy of $\mathrm{AX}$ conformers compared EQ conformers was determined to be $\Delta_{\mathrm{r}} H_{\mathrm{AX}} \approx 8 \mathrm{~kJ} \mathrm{~mol}^{-1}$. In 2003, two independent experimental studies showed that EQg conformer of carvone is the most abundant conformer (about 60\%) at ambient temperatures [42] and at $401 \mathrm{~K}$ [43]. Our calculations at the B3LYP-D3/6$311+G(d, p)$ level of theory predict a comparable population (54\%) of EQg conformer among the EQ conformers at $298.15 \mathrm{~K}$. Except the studies by Moreno and collaborators [44,45], there is an agreement about the order of stability of EQ conformers (see Table 8). As can be noticed (disregarding the results obtained in Refs. [44,45]), MP2 calculations predict slightly higher relative electronic energies of EQt and EQg and significantly lower relative electronic energies of

Table 7

Overview of the literature vapor pressure data.

\begin{tabular}{|c|c|c|c|c|c|c|}
\hline Reference $^{\mathrm{a}}$ & $n^{\mathrm{b}}$ & $\left(T_{\min }-T_{\max }\right) / \mathrm{K}$ & $\left(p_{\min }-p_{\max }\right) / \mathrm{Pa}$ & $u(p) / \mathrm{Pa}$ & Purity & Method \\
\hline \multicolumn{7}{|c|}{ Carvone (enantiopure) } \\
\hline Widegren and Bruno [32] & 4 & $283.2-313.2$ & $2.61-26.0$ & $0.14 p^{c}$ & $0.985^{\mathrm{d}}$ & Gas saturation \\
\hline Buchi and Erickson [33] & 2 & $360.6-382.4$ & $933-2067$ & $-e^{-T}$ & $-{ }^{e}$ & Ebulliometry \\
\hline Batiu and Jimenez Esteller [27] & 8 & $386.3-413.3$ & $2106-6919$ & $0.001 p$ & $0.998^{\mathrm{d}}$ & Ebulliometry \\
\hline Guetachew et al. [3] & 19 & $273.5-422.2$ & $1.43-9976$ & $0.02 p$ to $0.003 p$ & $0.999^{\mathrm{d}}$ & Static \\
\hline Batiu et al. [28] & 1 & 412.1 & 6665 & $-e^{e}$ & $0.999^{\mathrm{d}}$ & Ebulliometry \\
\hline Batiu [29] & 9 & $395.0-414.5$ & $3413-7433$ & $-\mathrm{e}$ & $0.999^{\mathrm{d}}$ & Ebulliometry \\
\hline This work & 36 & $258.2-308.2$ & $0.20-24.15$ & $0.005 p+0.05^{c}$ & $0.991^{\mathrm{d}}$ & Static \\
\hline \multicolumn{7}{|c|}{ Eugenol } \\
\hline van Roon et al. [35] & 1 & 298.15 & 2.98 & 0.29 & $\geq 0.970$ & Gas chromatography \\
\hline Russo et al. [34] & 14 & $281.1-343.5$ & $0.3-68.69$ & $0.025 p+0.005^{\mathrm{c}, \mathrm{f}}$ & $>0.9995$ & Gas saturation \\
\hline This work & 24 & $273.7-308.2$ & $0.15-4.87$ & $0.005 p+0.05^{c}$ & $1.000^{\mathrm{d}}$ & Static \\
\hline
\end{tabular}

a References in bold were included in the SimCor method.

b Number of experimental points.

c Expanded uncertainty (0.95 level of confidence).

d Measured by GC.

e Information not available.

${ }^{\mathrm{f}}$ For pressures below $5 \mathrm{~Pa}$; for pressures above $5 \mathrm{~Pa}, u(p / \mathrm{Pa})=0.025 p+0.025$. 

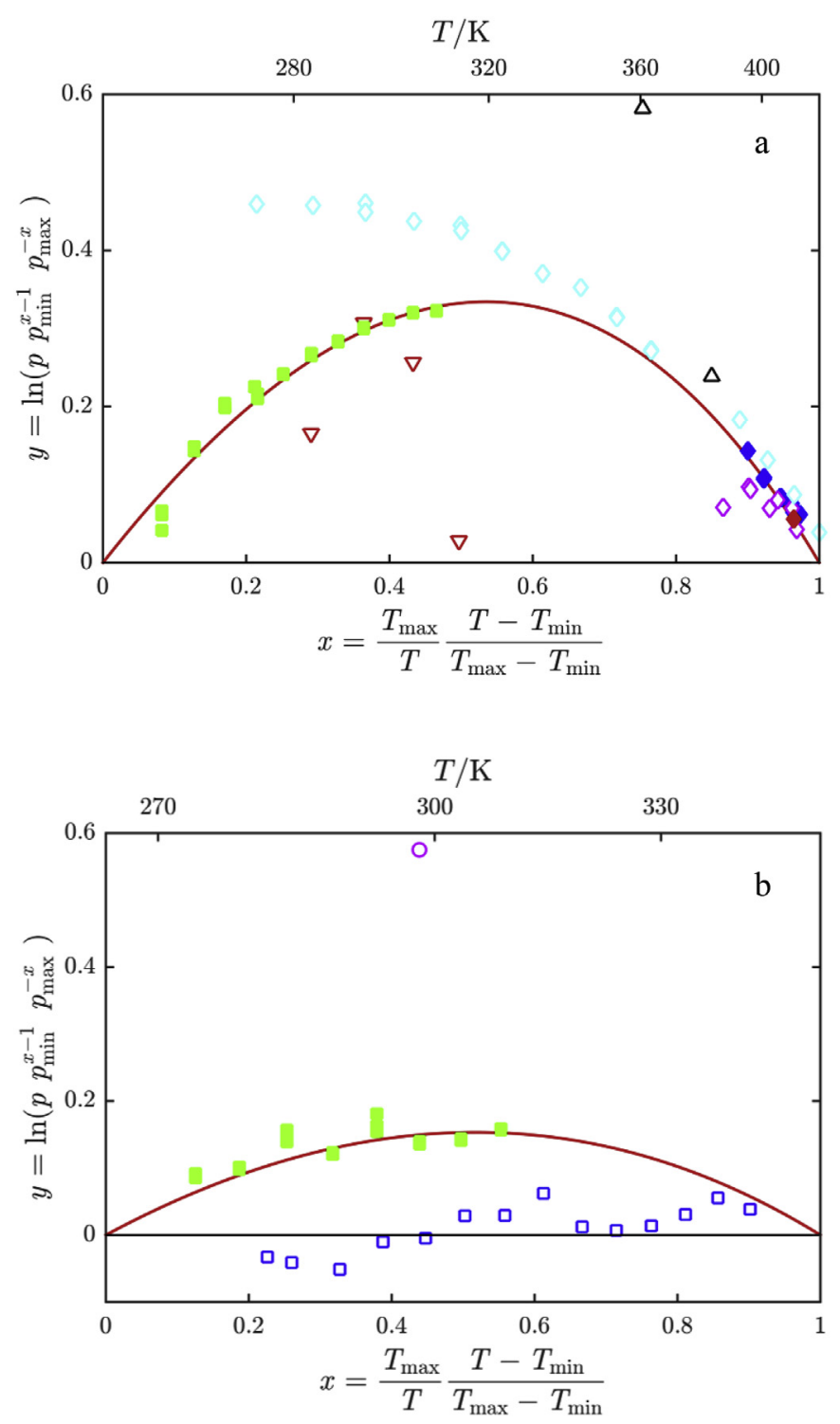

Fig. 4. Arc representation [26] of vapor pressures of liquid enantiopure carvone (a) and eugenol (b). $\ldots$, this work; $\triangle$, Buchi and Erickson [33]; $\bullet$, Batiu and Jimenez Esteller [27]; $\diamond$, Batiu et al. [28]; $\diamond$, Guetachew et al. [3]; $\diamond$, Batiu [29]; $\nabla$, Widegren and Bruno [32]; O, van Roon et al. [35]; 口, Russo et al. [34]; — curvature based on $\Delta_{1}^{\mathrm{g}} C_{p . \mathrm{m}}^{0}$ from calorimetrically determined liquid-phase heat capacities (Section 3.2) and ideal-gas heat capacities obtained by theoretical calculations (Section 3.4). References given in bold were accepted for the SimCor method (see Section 2.6).
AX conformers compared to DFT calculations. The relative energies of AX conformers, as predicted by MP2 method, lie in the range of $1.4-4.3 \mathrm{~kJ} \mathrm{~mol}^{-1}$ which is in disagreement with the experimental estimate of $8 \mathrm{~kJ} \mathrm{~mol}^{-1}$. The results obtained at B3LYP-D3/6$311+G(d, p)$ level of theory were considered as the most reliable and were used in the subsequent statistical thermodynamics calculations of ideal-gas thermodynamic properties by the R1SM model.

A conformational space of eugenol is formed by rotations of four tops, vinyl, prop-2-enyl, hydroxyl, and methoxyl, as visualized in Fig. 5. The two groups of tops separated in the conformer label by a dash, $\varphi \chi-\rho \varsigma$, rotate independently, but a strong coupling is observed in the prop-2-enyl top, which only occurs in ge', dc, or ee position, with dihedral angles labeled as eclipsed (e, $\left.120^{\circ}\right)$, antieclipsed $\left(e^{\prime},-120^{\circ}\right)$, distorted gauche $\left(\mathrm{d},-90^{\circ}\right)$, and cis $\left(\mathrm{c}, 0^{\circ}\right)$. Longarte et al. $[46,47]$ experimentally and theoretically determined ge'-tc conformer to be the most stable followed by dc-tc and stated that the third and last hydrogen-bonded conformer, ee-tc, could not be experimentally observed due to its low interconversional barrier. It was only observed later [48] without a possibility to determine stability compared to dc-tc. A more extensive list of 12 conformers was later reported in Ref. [48], which is in agreement with our findings. Other nine conformers however possess very high $\Delta_{\mathrm{r}} H_{i}^{0 \mathrm{~K}}$ and have a little impact on the ideal-gas properties. As evident from Table 9, all the studies agree that ge'-tc conformer is the lowest energy structure. However, there is an ambiguity about the relative stability of the conformers dc-tc and ee-tc. Therefore, beside the calculation at B3LYP-D3/6-311 $+\mathrm{G}(\mathrm{d}, \mathrm{p})$ level of theory additional calculations at B3LYP/6-311+G(d,p) and MP2/6-311+G(d,p) levels of theory were performed to resolve this issue. Both MP2 and B3LYP-D3 methods suggest that dc-tc conformer is more stable than ee-tc conformer while B3LYP predicts the opposite order. This disagreement can be attributed to well-known difficulties of B3LYP functional in treating dispersion interactions, as discussed in more detail in our previous work [21]. Therefore, it is believed that the stability of conformers and their relative energies (used as inputs in R1SM model) obtained by B3LYP-D3 method in this work are more reliable.

The ideal-gas thermodynamic properties presented in Table 10 were calculated by the R1SM model using of all stable conformers listed in Table S1, scaled harmonic frequencies, and methyl rotation parameters in Table S2. No literature studies on ideal-gas thermodynamic properties of the studied compounds were found for comparison.
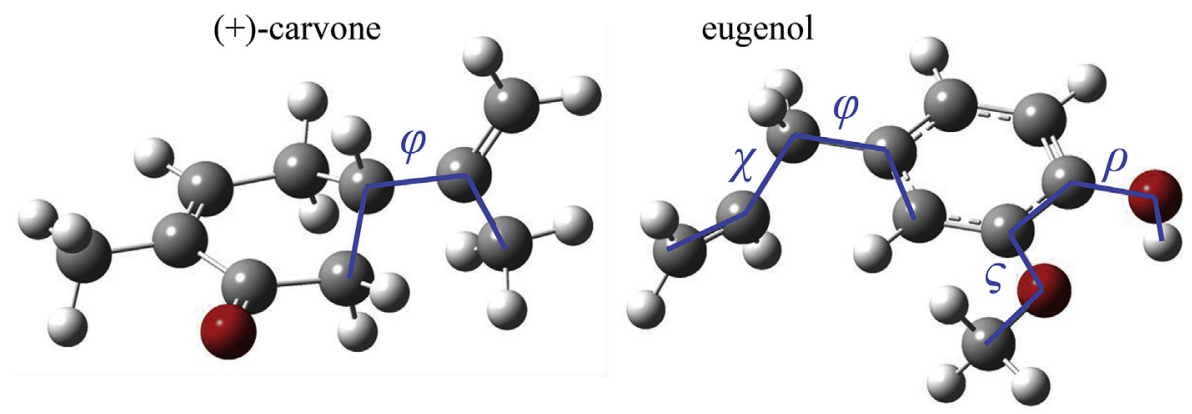

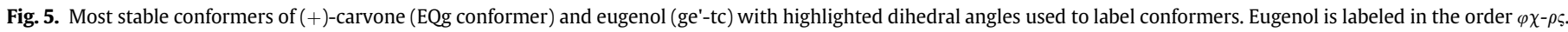


Table 8

Conformers of $(+)$-carvone and their relative energies in $\mathrm{kJ} \mathrm{mol}^{-1}$.

\begin{tabular}{|c|c|c|c|c|c|c|c|}
\hline \multirow{6}{*}{ Labels } & This work & EQg & EQg' & EQt & $\mathrm{AXg}$ & $\mathrm{AXg}^{\prime}$ & AXt \\
\hline & [42] & CE1 & CE3 & CE2 & CA3 & CA1 & CA2 \\
\hline & [43] & eq-1 & eq-2 & eq-3 & ax-1 & $\mathrm{ax}-2$ & $\mathrm{ax}-3$ \\
\hline & [49] & 1 (eq) & $2(\mathrm{eq})$ & $3(\mathrm{eq})$ & $1(\mathrm{ax})$ & $2(a x)$ & $3(\mathrm{ax})$ \\
\hline & {$[44,45]$} & EQ-1 & EQ-3 & EQ-2 & $\mathrm{AX}-1$ & $\mathrm{AX}-3$ & $A X-2$ \\
\hline & [50] & E1 & E2 & E3 & A1 & A2 & A3 \\
\hline \multirow{10}{*}{$\Delta_{r} E_{i}^{0 \mathrm{Ka}}$} & B3LYP-D3/6-311+G(d,p) ${ }^{\mathrm{b}}$ & 0 & 1.78 & 1.36 & 5.19 & 6.32 & 5.56 \\
\hline & B3PW91/6-31G(d) [42] & 0 & 1.37 & 1.05 & $\approx 19$ & 8.51 & $\approx 11$ \\
\hline & B3LYP/6-31G(d,p) [43] & 0 & 1.25 & 1.09 & 8.87 & 8.58 & 7.57 \\
\hline & B3LYP/6-31G(d,p) [44] & 1.1 & 2.0 & 0 & - & - & - \\
\hline & B3LYP/cc-pVDZ [45] & 0.93 & 0.98 & 0 & 9.06 & 8.68 & 7.88 \\
\hline & B3LYP/6-31G(d,p) [50] & 0 & 1.28 & 1.08 & 8.85 & 8.59 & 7.56 \\
\hline & MP2/6-31G(d,p) [43] & 0 & 2.59 & 1.67 & 4.31 & 3.35 & 1.55 \\
\hline & $\mathrm{MP} 2 / 6-311++\mathrm{G}(2 \mathrm{df}, \mathrm{p})[44]$ & 1.1 & 2.0 & 0 & - & - & - \\
\hline & MP2(full)/6-311++G(3df,2p) [44] & 1.1 & 2.0 & 0 & - & - & - \\
\hline & MP2/6-31G(d,p) [50] & 0 & 2.55 & 1.64 & 4.1 & 3.16 & 1.36 \\
\hline \multirow{3}{*}{$\Delta_{\mathrm{r}} H_{i}^{0} \mathrm{Ka}$} & B3LYP-D3/6-311+G(d,p) $)^{b}$ & 0 & 2.11 & 1.64 & 5.54 & 6.85 & 6.08 \\
\hline & B3LYP/cc-pVDZ [45] & 0.98 & 1.19 & 0 & 9.49 & 9.09 & 8.56 \\
\hline & G3 method [49] & 0 & 0.48 & 0.28 & 6.4 & 3.4 & 3.0 \\
\hline
\end{tabular}

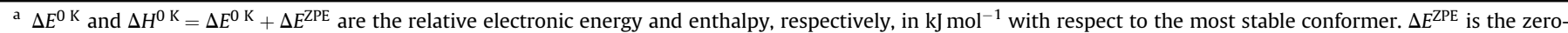
point vibrational energy.

b This work.

Table 9

Most stable conformers of eugenol and their relative energies in $\mathrm{kJ} \mathrm{mol}^{-1}$.

\begin{tabular}{|c|c|c|c|c|}
\hline Labels & $\begin{array}{r}\text { This work } \\
{[46,47]} \\
{[48]} \\
{[51]} \\
{[52]}\end{array}$ & $\begin{array}{l}\text { ge'-tc } \\
1 \mathrm{a} \\
\text { SAA+ } \\
1 \\
\text { config1 }\end{array}$ & $\begin{array}{l}\text { dc-tc } \\
2 \\
\text { SAS } \\
3 \\
-\end{array}$ & $\begin{array}{l}\text { ee-tc } \\
1 \mathrm{~b} \\
\text { SAA- } \\
2 \\
\text { config2 }\end{array}$ \\
\hline \multirow{7}{*}{$\Delta_{\mathrm{r}} E_{i}^{0 \mathrm{Ka}}$} & B3LYP-D3/6-311+G(d,p) $)^{b, c}$ & 0 & 0.83 & 2.28 \\
\hline & B3LYP/6-311+G(d,p) $)^{b}$ & 0 & 2.78 & 1.89 \\
\hline & $\mathrm{MP} 2 / 6-311+\mathrm{G}(\mathrm{d}, \mathrm{p})^{\mathrm{b}}$ & 0 & 0.44 & 2.42 \\
\hline & B3LYP/6-31++G(2d,p) [47] & 0 & 3.21 & 1.79 \\
\hline & B3LYP/6-311++G(2d,2p) [48] & 0 & 2.78 & 1.77 \\
\hline & B3LYP/cc-pVTZ [51] & 0 & 3.03 & 1.77 \\
\hline & MP2/6-311G(d) [47] & 0 & 0.86 & - \\
\hline \multirow{6}{*}{$\Delta_{\mathrm{r}} H_{i}^{0} \mathrm{Ka}$} & B3LYP/6-311+G(d,p) $)^{\mathrm{b}}$ & 0 & 2.71 & 1.64 \\
\hline & B3LYP-D3/6-311+G(d,p) $)^{\mathrm{b}, \mathrm{c}}$ & 0 & 0.96 & 2.04 \\
\hline & B3LYP/6-31++G(2d,p) [47] & 0 & 3.07 & 1.53 \\
\hline & B3LYP/6-311++G(2d,2p) [48] & 0 & 2.72 & 1.62 \\
\hline & B3LYP/6-311+G(d,p) [52] & 0 & - & 1.63 \\
\hline & MP2/6-311G(d) [47] & 0 & 0.97 & - \\
\hline
\end{tabular}

${ }^{\mathrm{a}} \Delta E^{0 \mathrm{~K}}$ and $\Delta H^{0 \mathrm{~K}}=\Delta E^{0 \mathrm{~K}}+\Delta E^{\mathrm{ZPE}}$ are the relative electronic energy and enthalpy, respectively, in $\mathrm{kJ} \mathrm{mol}^{-1}$ with respect to the most stable conformer. $\Delta E^{\mathrm{ZPE}}$ is the zero-point vibrational energy.

b This work.

c The results obtained at B3LYP-D3/6-311+G(d,p) level of theory are considered as the most reliable and they were used in the subsequent calculations of ideal-gas thermodynamic properties using the R1SM model.

\subsection{SimCor results and mutual consistency of the studied thermodynamic properties}

The selected vapor pressure data (bold in Table 7) were treated simultaneously with the $\Delta_{1}^{\mathrm{g}} C_{p, \mathrm{~m}}^{0}$ calculated from ideal-gas heat capacities obtained by statistical thermodynamics model R1SM (Section 3.4) and the experimental liquid-phase heat capacities (Section 3.2). The Clarke and Glew equation, Eq. (2), with 4 parameters was used as correlation equation in the SimCor method. The difference between the experimental and calculated (by the SimCor method) vapor pressures, $\Delta p=p-p_{\text {calc, }}$ are shown in Table 6. The parameters of the Clarke and Glew equation along with the standard relative deviations of the fit, $\sigma_{\mathrm{r}}$, are shown in Table 11. Deviations of vapor pressure data from the SimCor results are displayed in Fig. 6. Vapor pressure data for eugenol recently reported by Russo et al. [34], which became available to us during the
Table 10

Standard molar thermodynamic functions of carvone and eugenol in the ideal gaseous state (in $\mathrm{J} \mathrm{K}^{-1} \mathrm{~mol}^{-1}$ ) at $p=100 \mathrm{kPa}$ calculated using the R1SM model. ${ }^{\text {a }}$

\begin{tabular}{|c|c|c|c|c|c|c|}
\hline \multirow[t]{3}{*}{$T / K$} & $C_{p, \mathrm{~m}}^{\mathrm{g} 0}$ & $S_{\mathrm{m}}^{\mathrm{g} 0}$ & $\Delta_{0}^{T} H_{\mathrm{m}}^{\mathrm{g} 0} / T$ & \multirow{2}{*}{$\frac{C_{p, \mathrm{~m}}^{\mathrm{g} 0}}{\text { Eugeno }}$} & $S_{\mathrm{m}}^{\mathrm{g} 0}$ & $\Delta_{0}^{T} H_{\mathrm{m}}^{\mathrm{g} 0} / T$ \\
\hline & \multicolumn{3}{|c|}{ Carvone (enantiopure) } & & & \\
\hline & \multicolumn{3}{|c|}{$\mu(298.15 \mathrm{~K})=3.56 \mathrm{D}^{\mathrm{b}}$} & \multicolumn{3}{|c|}{$\mu(298.15 \mathrm{~K})=2.77 \mathrm{D}^{\mathrm{b}}$} \\
\hline 200 & 143.0 & 388.0 & 89.7 & 145.0 & 404.6 & 90.6 \\
\hline 210 & 147.9 & 395.1 & 92.3 & 150.6 & 411.8 & 93.3 \\
\hline 220 & 153.0 & 402.1 & 94.9 & 156.1 & 419.0 & 96.0 \\
\hline 230 & 158.0 & 409.0 & 97.5 & 161.8 & 426.1 & 98.8 \\
\hline 240 & 163.2 & 415.9 & 100.1 & 167.4 & 433.2 & 101.5 \\
\hline 250 & 168.4 & 422.6 & 102.7 & 173.1 & 440.2 & 104.3 \\
\hline 260 & 173.6 & 429.4 & 105.3 & 178.9 & 447.1 & 107.0 \\
\hline 270 & 178.9 & 436.0 & 107.9 & 184.6 & 454.0 & 109.8 \\
\hline 273.15 & 180.6 & 438.1 & 108.7 & 186.4 & 456.2 & 110.7 \\
\hline 280 & 184.3 & 442.6 & 110.5 & 190.4 & 460.9 & 112.6 \\
\hline 290 & 189.7 & 449.2 & 113.1 & 196.1 & 467.7 & 115.4 \\
\hline 298.15 & 194.1 & 454.5 & 115.3 & 200.8 & 473.2 & 117.6 \\
\hline 300 & 195.1 & 455.7 & 115.8 & 201.9 & 474.5 & 118.1 \\
\hline 310 & 200.5 & 462.2 & 118.4 & 207.6 & 481.2 & 120.9 \\
\hline 320 & 205.9 & 468.6 & 121.0 & 213.3 & 487.9 & 123.7 \\
\hline 330 & 211.3 & 475.0 & 123.6 & 219.0 & 494.6 & 126.5 \\
\hline 340 & 216.7 & 481.4 & 126.3 & 224.7 & 501.3 & 129.3 \\
\hline 350 & 222.1 & 487.8 & 128.9 & 230.3 & 507.9 & 132.2 \\
\hline 360 & 227.4 & 494.1 & 131.6 & 235.9 & 514.5 & 135.0 \\
\hline 370 & 232.7 & 500.4 & 134.2 & 241.4 & 521.1 & 137.8 \\
\hline 380 & 238.0 & 506.7 & 136.9 & 246.8 & 527.6 & 140.6 \\
\hline 390 & 243.2 & 513.0 & 139.5 & 252.2 & 534.1 & 143.4 \\
\hline 400 & 248.3 & 519.2 & 142.1 & 257.5 & 540.6 & 146.1 \\
\hline 500 & 296.1 & 579.9 & 168.2 & 306.0 & 603.6 & 173.4 \\
\hline 600 & 336.4 & 637.5 & 192.9 & 346.4 & 663.2 & 199.0 \\
\hline 700 & 370.3 & 692.0 & 215.9 & 379.3 & 719.3 & 222.5 \\
\hline
\end{tabular}

a The standard uncertainties ( 0.68 level of confidence) are estimated to be $0.005 C_{p . \mathrm{m}}^{\mathrm{g} 0}, 0.005 S_{\mathrm{m}}^{\mathrm{g} 0}$, and $0.006 H_{\mathrm{m}}^{\mathrm{g} 0}$.

b Dipole moment at $298.15 \mathrm{~K}$ in Debye calculated using mixing model.

revision process, deviate from the developed vapor pressure equation on average by $11 \%$ (the deviations range from -17 to $-2 \%$ ).

The vaporization enthalpies obtained from the SimCor method were (including standard uncertainties): $\Delta_{1}^{\mathrm{g}} H_{\mathrm{m}}^{0}(298.15 \mathrm{~K})=$ $(61.62 \pm 0.12) \mathrm{kJ} \mathrm{mol}^{-1}$ for $(+)$-carvone (no data for comparison) and $\Delta_{1}^{\mathrm{g}} H_{\mathrm{m}}^{0}(298.15 \mathrm{~K})=(69.8 \pm 1.0) \mathrm{kJ} \mathrm{mol}^{-1}$ for eugenol, which agrees with the value of $\Delta_{\mathrm{l}}^{\mathrm{g}} H_{\mathrm{m}}^{0}(298.15 \mathrm{~K})=(70.9 \pm 0.3) \mathrm{kJ} \mathrm{mol}^{-1}$ recently determined by Russo et al. [34] within estimated 
Table 11

Parameters of the Clarke and Glew equation, Eq (2), at selected reference temperature $\theta=298.15 \mathrm{~K}$ and pressure $p^{0}=10^{5} \mathrm{~Pa}$.

\begin{tabular}{|c|c|c|c|c|c|c|}
\hline Compound (phase) & $\left(T_{\min }-T_{\max }\right) / \mathrm{K}^{\mathrm{a}}$ & $\Delta_{1}^{\mathrm{g}} G_{\mathrm{m}}^{0} / \mathrm{J} \mathrm{mol}{ }^{-1}$ & $\Delta_{\mathrm{l}}^{\mathrm{g}} H_{\mathrm{m}}^{0} / \mathrm{J} \mathrm{mol}{ }^{-1}$ & $\Delta_{1}^{\mathrm{g}} C_{p, \mathrm{~m}}^{0} / \mathrm{J} \mathrm{K}^{-1} \mathrm{~mol}^{-1}$ & $\frac{\partial \Delta_{l}^{\mathrm{g}} C_{p, \mathrm{~m}}^{0}}{\partial T} / \mathrm{J} \mathrm{K}^{-2} \mathrm{~mol}^{-1}$ & $\sigma_{\mathrm{rb}^{\mathrm{b}}}$ \\
\hline Enantiopure carvone (l) & $250-415$ & $22631.9 \pm 2.9^{c}$ & $61621.8 \pm 51.7$ & $-83.375 \pm 0.299$ & $0.0949 \pm 0.0090$ & 0.015 \\
\hline Eugenol (1) & $265-335$ & $26887.6 \pm 6.3$ & $69819.3 \pm 235.7$ & $-121.504 \pm 0.249$ & $0.2230 \pm 0.0116$ & 0.021 \\
\hline
\end{tabular}

a Parameters developed by the SimCor method are valid over a combined temperature interval of the input thermodynamic data.

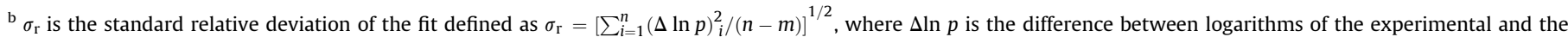
smoothed values, $n$ is the number of experimental points used in the fit and $m$ is the number of adjustable parameters of Clarke and Glew equation, Eq (2).

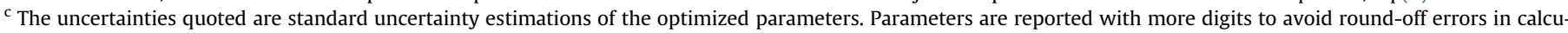
lations based on the correlation.
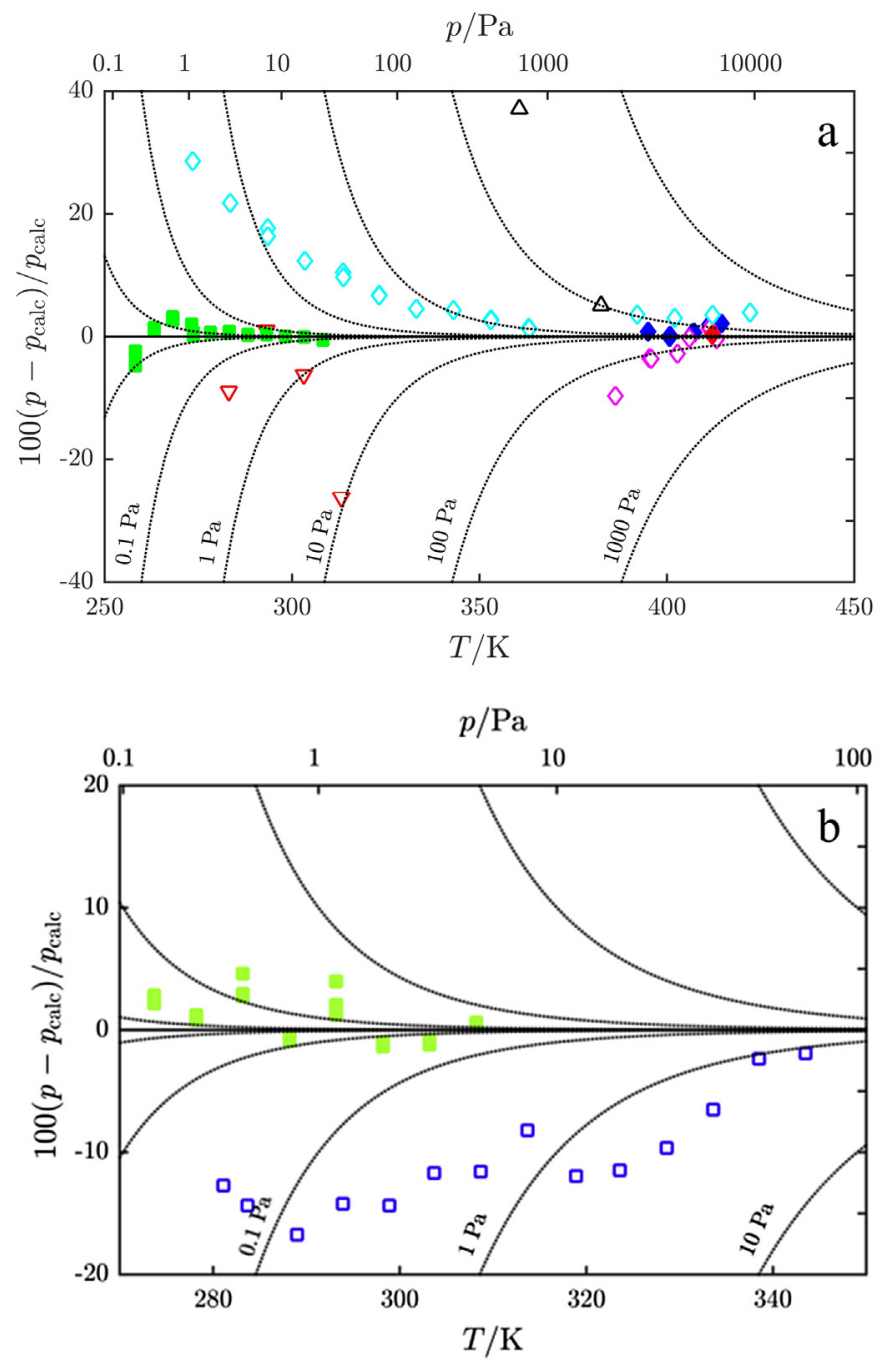

Fig. 6. Deviation plots for vapor pressures of liquid enantiopure carvone (a) and eugenol (b). $\ldots$, this work; $\triangle$, Buchi and Erickson [33]; $\diamond$, Batiu et al. [28]; $\diamond$, Batiu and Jimenez Esteller [27]; $\diamond$, Guetachew et al. [3]; $\diamond$, Batiu [29]; $\nabla$, Widegren and Bruno [32]; $\square$, Russo et al. [34]; -unn, absolute deviations. Data point reported for eugenol by van Roon et al. [35] is out of scale.

experimental uncertainties. $\Delta_{1}^{\mathrm{g}} C_{p, \mathrm{~m}}^{0}$ values derived from calorimetrically determined liquid-phase heat capacities and ideal-gas heat capacities obtained by theoretical calculations with those resulting from the SimCor method are compared in Fig. 7. An excellent agreement can be noticed. For eugenol, $\Delta_{1}^{\mathrm{g}} C_{p, \mathrm{~m}}^{0}(298.15 \mathrm{~K})=-(83 \pm 3) \mathrm{J} \mathrm{K}^{-1} \mathrm{~mol}^{-1}$ was recently obtained from vapor pressure measurements by Russo et al. [34] which differs by about $38 \mathrm{~J} \mathrm{~K}^{-1} \mathrm{~mol}^{-1}$ from the value obtained from liquid-phase and ideal-gas heat capacities in this work.

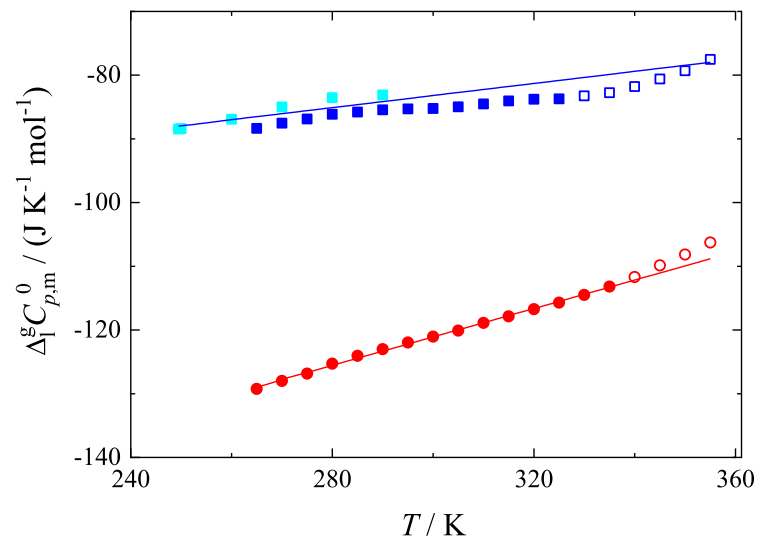

Fig. 7. Temperature dependence of $\Delta_{1}^{\mathrm{g}} C_{p, \mathrm{~m}}^{0}=C_{p, \mathrm{~m}}^{\mathrm{g} 0}-C_{p, \mathrm{~m}}^{\mathrm{l}}$. Enantiopure carvone: $C_{p, \mathrm{~m}}^{\mathrm{l}}$ (Table 4), and $C_{p, \mathrm{~m}}^{\mathrm{g} 0}$ (Table 10); $\square C_{p, \mathrm{~m}}^{\mathrm{l}}$ (Table 4), and $C_{p, \mathrm{~m}}^{\mathrm{g} 0}$ (Table 10), excluded due to large $p V T$ correction; $\square C_{p, \mathrm{~m}}^{\mathrm{l}}$ (adiabatic calorimetry [23]), and $C_{p, \mathrm{~m}}^{\mathrm{g} 0}$ (Table 10); $\Delta_{1}^{\mathrm{g}} C_{p, \mathrm{~m}}^{0}$ obtained by SimCor method. Eugenol: $\bullet C_{p, \mathrm{~m}}^{\mathrm{l}}$ (Table 4), and $C_{p, \mathrm{~m}}^{\mathrm{g} 0}$ (Table 10); $\bigcirc$ $C_{p, \mathrm{~m}}^{\mathrm{l}}$ (Table 4), and $C_{p, \mathrm{~m}}^{\mathrm{g} 0}$ (Table 10 ), excluded due to large $p V T$ correction; $\Delta_{l}^{g} C_{p, \mathrm{~m}}^{0}$ obtained by SimCor method. Data points represented by filled symbols were included in the SimCor method.

Finally, the overall consistency of presented thermodynamic data can be verified by comparing standard ideal-gas entropies obtained by combining statistical thermodynamics and quantum chemical calculations with those obtained from experimental data on heat capacities of condensed phases (performed from near $0 \mathrm{~K}$ ) and vapor pressure measurements. For (-)-carvone, Gallis et al. [23] reported calorimetrically obtained molar liquid entropy $S_{\mathrm{m}}^{\mathrm{l}}(290 \mathrm{~K})=314.26 \pm 0.63 \mathrm{~J} \mathrm{~K}^{-1} \mathrm{~mol}^{-1}$, which in combination with the standard vaporization entropy $\Delta_{1}^{\mathrm{g}} S_{\mathrm{m}}^{0}(290 \mathrm{~K})$ $=133.09 \pm 0.41 \mathrm{~J} \mathrm{~K}^{-1} \mathrm{~mol}^{-1}$ obtained from the SimCor method results in $S_{\mathrm{m}}^{\mathrm{g} 0}(290 \mathrm{~K})=447.35 \pm 0.75 \mathrm{~J} \mathrm{~K}^{-1} \mathrm{~mol}^{-1}$. This value compares well with $S_{\mathrm{m}}^{\mathrm{g} 0}(290 \mathrm{~K})=449.2 \pm 2.4 \mathrm{~J} \mathrm{~K}^{-1} \mathrm{~mol}^{-1}$ obtained for enantiopure carvone by theoretical calculations using R1SM model (the two values agree within their uncertainties).

\section{Conclusions}

Thermodynamically consistent vapor pressure equations for eugenol and enantiopure carvone were developed by a multiproperty correlation of thermodynamically linked properties over an environmentally relevant range of temperatures. Required input thermodynamic data for the multi-property correlation, i.e. vapor pressures, liquid-phase heat capacities, and ideal-gas thermodynamic properties, were newly obtained in this work. To our knowledge, many of the abovementioned properties are reported for the first time in this work. The phase behavior studies revealed the existence of two monotropically related crystalline forms of eugenol that are, to our knowledge, also described for the first time 
in this work. The fusion thermodynamic properties of both crystalline forms were determined.

\section{Acknowledgments}

The authors M.F., K.R., V.Š., and V.P. acknowledge financial support from the Czech Science Foundation (GACR no. 17-03875S) and specific university research (MSMT No. 20-SVV/2018). The authors S.M.V., O.F., and S.P.P. acknowledge financial support from the project POCI-01-0145-FEDER-006984 - Associate Laboratory LSRE-LCM (UID/EQU/50020/2019) funded by national funds through FCT/MCTES (PIDDAC). S.M.V. also acknowledges FCT for his PhD grant (SFRH/BD/138149/2018).

\section{Appendix A. Supplementary data}

Supplementary data to this article can be found online at https://doi.org/10.1016/j.fluid.2019.112248.

\section{References}

[1] S. Zwenger, C. Basu, Plant terpenoids: applications and future potentials, Biotechnol. Mol. Biol. Rev. 3 (2008) 1-6.

[2] M. Eggersdorfer, Terpenes, Ullmann's encycl, Ind. Chem. 36 (2012) 29-45.

[3] T. Guetachew, I. Mokbel, I. Batiu, Z. Cisse, J. Jose, Vapor pressures and sublimation pressures of eight constituets of essential oils at pressures in the range from 0.3 to 83,000 Pa, ELDATA Int. Electron. J. Phys. Chem. Data 5 (1999) $43-53$.

[4] J. Bohlmann, C.I. Keeling, Terpenoid biomaterials, Plant J. 54 (2008) 656-669.

[5] J. Panten, H. Surburg, Flavor fragrances, 3. Aromatic and heterocyclic compounds, in: Ullmann's Encycl. Ind. Chem., 2015, pp. 1-45.

[6] C.C.C.R. de Carvalho, M.M.R. Fonseca, Carvone: why and how should one bother to produce this terpene, Food Chem. 95 (2006) 413-422.

[7] G.P. Kamatou, I. Vermaak, A.M. Viljoen, Eugenol - from the remote Maluku Islands to the international market place: a review of a remarkable and versatile molecule, Molecules 17 (2012) 6953-6981.

[8] M. Claeys, B. Graham, G. Vas, W. Wang, R. Vermeylen, V. Pashynska, J. Cafmeyer, P. Guyon, M.O. Andreae, P. Artaxo, W. Maenhaut, Formation of secondary organic aerosols through photooxidation of isoprene, Science 303 (2004) 1173-1176.

[9] J.H. Kroll, N.L. Ng, S.M. Murphy, R.C. Flagan, J.H. Seinfeld, Secondary organic aerosol formation from isoprene photooxidation, Environ. Sci. Technol. 40 (2006) 1869-1877.

[10] R. Valorso, B. Aumont, M. Camredon, T. Raventos-Duran, C. Mouchel-Vallon, N.L. Ng, J.H. Seinfeld, J. Lee-Taylor, S. Madronich, Explicit modelling of SOA formation from $\alpha$-pinene photooxidation: sensitivity to vapour pressure estimation, Atmos. Chem. Phys. 11 (2011) 6895-6910.

[11] B. Bonn, R. von Kuhlmann, M.G. Lawrence, High contribution of biogenic hydroperoxides to secondary organic aerosol formation, Geophys. Res. Lett. 31 (2004) 1-4.

[12] M. Kanakidou, J.H. Seinfeld, S.N. Pandis, I. Barnes, F.J. Dentener, M.C. Facchini, R. van Dingenen, B. Ervens, A. Nenes, C.J. Nielsen, E. Swietlicki, J.P. Putaud, Y. Balkanski, S. Fuzzi, J. Horth, G.K. Moortgat, R. Wienterhalter, C.E.L. Myhre K. Tsigaridis, E. Vignati, E.G. Stephanou, J. Wilson, Organic aerosol and global climate modelling: a review, Atmos. Chem. Phys. 5 (2005) 1053-1123.

[13] K. Rủžička, V. Majer, Simultaneous treatment of vapor-pressures and related thermal data between the triple and normal boiling temperatures for $n$-alkanes $C_{5}-C_{20}$ J. Phys. Chem. Ref. Data 23 (1994) 1-39.

[14] J. Meija, T.B. Coplen, M. Berglund, W.A. Brand, P. De Bièvre, M. Gröning, N.E. Holden, J. Irrgeher, R.D. Loss, T. Walczyk, T. Prohaska, Atomic weights of the elements 2013 (IUPAC technical report), Pure Appl. Chem. 88 (2016) 265-291.

[15] P.J. Mohr, D.B. Newel, B.N. Taylor, CODATA Recommended values of the fundamental physical constants: 2014, J. Phys. Chem. Ref. Data 45 (2016) 1795-1803.

[16] G.W.H. Höhne, W.F. Hemminger, H.J. Flammersheim, Differential Scanning Calorimetry, Springer Heidelberg, Berlin, 2003.

[17] V. Štejfa, M. Fulem, K. Růžička, C. Červinka, Thermodynamic study of selected monoterpenes III, J. Chem. Thermodyn. 79 (2014) 280-289.

[18] M. Fulem, K. Rủžička, P. Morávek, J. Pangrác, E. Hulicius, B. Kozyrkin, V. Shatunov, Vapor pressure of selected organic iodides, J. Chem. Eng. Data 55 (2010) 4780-4784.

[19] M.J. Frisch, G.W. Trucks, H.B. Schlegel, G.E. Scuseria, M.A. Robb, J.R. Cheeseman, G. Scalmani, V. Barone, B. Mennucci, G.A. Petersson, H. Nakatsuji, M. Caricato, X. Li, H.P. Hratchian, A.F. Izmaylov, J. Bloino, G. Zheng, J.L. Sonnenberg, M. Hada, M. Ehara, K. Toyota, R. Fukuda, J. Hasegawa, M. Ishida, T. Nakajima, Y. Honda, O. Kitao, H. Nakai, T. Vreven, J.A. Montgomery, J.E. Peralta, F. Ogliaro, M. Bearpark, J.J. Heyd, E. Brothers,
K.N. Kudin, V.N. Staroverov, T. Keith, R. Kobayashi, J. Normand, K. Raghavachari, A. Rendell, J.C. Burant, S.S. Iyengar, J. Tomasi, M. Cossi, N. Rega, J.M. Millam, M. Klene, J.E. Knox, J.B. Cross, V. Bakken, C. Adamo, J. Jaramillo, R. Gomperts, R.E. Stratmann, O. Yazyev, A.J. Austin, R. Cammi, C. Pomelli, J.W. Ochterski, R.L. Martin, K. Morokuma, V.G. Zakrzewski, G.A. Voth, P. Salvador, J.J. Dannenberg, S. Dapprich, A.D. Daniels, O. Farkas, J.B. Foresman, J. V Ortiz, J. Cioslowski, D.J. Fox, Gaussian 09, Revision D.01, Gaussian, Inc., Wallingford CT, 2013.

[20] S. Grimme, J. Antony, S. Ehrlich, H. Krieg, A consistent and accurate ab initio parametrization of density functional dispersion correction (DFT-D) for the 94 elements H-Pu, J. Chem. Phys. 132 (2010) 1-19.

[21] V. Štejfa, M. Fulem, K. Rủžička, First-principles calculation of ideal-gas thermodynamic properties of long-chain molecules by R1SM approachapplication to n-alkanes, J. Chem. Phys. 150 (2019) 224101.

[22] E.C.W. Clarke, D.N. Glew, Evaluation of the thermodynamic functions from equilibrium constants, Trans. Faraday Soc. 62 (1966) 539-547.

[23] H.E. Gallis, J.C. van Miltenburg, H.A.J. Oonk, J.P. van der Eerden, Mixtures of dand l-carvone. III. Thermodynamic properties of l-carvone, Thermochim. Acta 286 (1996) 307-319.

[24] H.E. Gallis, F. Bougrioua, H.A.J. Oonk, PJ. van Ekeren, J.C. van Miltenburg Mixtures of d- and l-carvone: I . Differential scanning calorimetry and solidliquid phase diagram, Thermochim. Acta 274 (1996) 231-242.

[25] M. Zábranský, V. Růžička, V. Majer, Heat Capacity of Liquids. Critical Review and Recommended Values, American Chemical Society, Washington, D.C, 1996.

[26] M. Čenský, V. Roháč, K. Růžička, M. Fulem, K. Aim, Vapor pressure of selected aliphatic alcohols by ebulliometry. Part 1, Fluid Phase Equilib. 298 (2010) 192-198.

[27] I. Batiu, L.J. Esteller, Vapor liquid equilibria in binary systems (+)-carvone + (+)-limonene at temperatures between 365 and 411 K, ELDATA Int. Electron. J. Phys. Chem. Data 2 (1996) 59-66.

[28] I. Batiu, J. Jose, I. Mokbel, L.J. Esteller, A.P. Bonsfills, Vapor-liquid equilibria in the binary systems methyl chavicol + eucalyptol and (-) carvone + eucalypotl at temperatures between $350 \mathrm{~K}$ and $412 \mathrm{~K}$, ELDATA Int. Electron. J. Phys. Chem. Data 4 (1998) 67-74.

[29] I. Batiu, Vapor-liquid equilibria in the binary system (R)-(-)-carvone + decane at temperatures between $342 \mathrm{~K}$ and $403 \mathrm{~K}$, ELDATA Int. Electron. J. Phys. Chem. Data 5 (1999) 191-195.

[30] V. Štejfa, M. Fulem, K. Rǔžička, C. Červinka, Thermodynamic study of selected monoterpenes II, J. Chem. Thermodyn. 79 (2014) 272-279.

[31] V. Štejfa, M. Fulem, K. Růžička, C. Cervinka, M.A.A. Rocha, L.M.N.B.F. Santos, B. Schröder, Thermodynamic study of selected monoterpenes, J. Chem. Thermodyn. 60 (2013) 117-125.

[32] J.A. Widegren, T.J. Bruno, Vapor pressure measurements on low-volatility terpenoid compounds by the concatenated gas saturation method, Environ. Sci. Technol. 44 (2010) 388-393.

[33] G. Büchi, R.E. Erickson, Terpenes II. The reactions of carvone and dihydrocarvone with methanol in the presence of sulfuric acid, J. Am. Chem. Soc. 76 (1954) 3493-3495.

[34] A.Y. Russo, M.E. Konnova, I.V. Andreeva, S.P. Verevkin, Vaporization thermodynamics of compounds modeling lignin structural units, Fluid Phase Equilib. 491 (2019) 45-55.

[35] A. van Roon, J.R. Parsons, H.A.J. Govers, Gas chromatographic determination of vapour pressure and related thermodynamic properties of monoterpenes and biogenically related compounds, J. Chromatogr. A 955 (2002) 105-115.

[36] K. Rǔzička, B. Koutek, M. Fulem, M. Hoskovec, Indirect determination of vapor pressures by capillary gas-liquid chromatography: analysis of the reference vapor-pressure data and their treatment, J. Chem. Eng. Data 57 (2012) 1349-1368.

[37] B. Koutek, T. Mahnel, P. Šimáček, M. Fulem, K. Růžička, Extracting vapor pressure data from GLC retention times. part 1: analysis of single reference approach, J. Chem. Eng. Data 62 (2017) 3542-3550.

[38] B. Koutek, M. Fulem, T. Mahnel, P. Šimáček, K. Růžička, Extracting vapor pressure data from gas-liquid chromatography retention times. Part 2: analysis of double reference approach, J. Chem. Eng. Data 63 (2018) 4649-4661.

[39] V. Štejfa, A. Bazyleva, M. Fulem, J. Rohlíček, E. Skořepová, K. Růžička, A.V. Blokhin, Polymorphism and thermophysical properties of L- and DLmenthol, J. Chem. Thermodyn. 131 (2019) 524-543.

[40] R.E. Ballard, S.F. Mason, G.W. Vane, Circular dichroism of dissymmetric $\alpha \beta-$ unsaturated ketones, Discuss. Faraday Soc. 35 (1963) 43-47.

[41] T. Suga, K. Imamura, Stereochemical studies of monoterpene compounds. XVIII. A conformational study of monoterpene $\alpha, \beta$-unsaturated ketones by means of the temperature-dependent circular dichroism, Bull. Chem. Soc. Jpn. 45 (1972) 2060-2064.

[42] G.G. Hoffmann, Infrared, Raman and VCD spectra of (S)-(+)-carvone-comparison of experimental and ab initio theoretical results, J. Mol. Struct. 661-662 (2003) 525-539.

[43] T. Egawa, Y. Kachi, T. Takeshima, H. Takeuchi, S. Konaka, Structural determination of carvone, a component of spearmint, by means of gas electron diffraction augmented by theoretical calculations, J. Mol. Struct. 658 (2003) $241-251$.

[44] J.R.A. Moreno, T.R. Huet, J.J.L. González, Conformational relaxation of S$(+)$-carvone and R-(+)-limonene studied by microwave Fourier transform spectroscopy and quantum chemical calculations, Struct. Chem. 24 (2013) 1163-1170. 
[45] J.R. Avilés Moreno, F. Partal Ureña, J.J. López González, Conformational landscape in chiral terpenes from vibrational spectroscopy and quantum chemical calculations: S-(+)-carvone, Vib. Spectrosc. 51 (2009) 318-325.

[46] A. Longarte, C. Redondo, J.A. Fernández, F. Castaño, IR/UV and UV/UV doubleresonance study of guaiacol and eugenol dimers, J. Chem. Phys. 122 (2005) $1-11$.

[47] A. Longarte, I. Unamuno, J.A. Fernández, F. Castaño, C. Redondo, Experimental and theoretical study of the structures and binding energies of eugenol $(\mathrm{H} 2 \mathrm{O})$ n , n=0-2, J. Chem. Phys. 121 (2004) 209-219.

[48] A. Olbert-Majkut, M. Wierzejewska, Conformational study of eugenol by density functional theory method and matrix-isolation infrared spectroscopy, J. Phys. Chem. A 112 (2008) 5691-5699.
[49] J. Lambert, R.N. Compton, T.D. Crawford, The optical activity of carvone: a theoretical and experimental investigation, J. Chem. Phys. 136 (2012) 1-12.

[50] C.J. Harding, I. Powis, Sensitivity of photoelectron circular dichroism to structure and electron dynamics in the photoionization of carvone and related chiral monocyclic terpenone enantiomers, J. Chem. Phys. 125 (2006) 234306.

[51] B.Z. Chowdhry, J.P. Ryall, T.J. Dines, A.P. Mendham, Infrared and Raman Spectroscopy of eugenol, isoeugenol, and methyl eugenol: conformational analysis and vibrational assignments from density functional theory calculations of the anharmonic fundamentals, J. Phys. Chem. A 119 (2015) $11280-11292$.

[52] A.M. Verma, N. Kishore, Gas phase conversion of eugenol into various hydrocarbons and platform chemicals, RSC Adv. 7 (2017) 2527-2543. 